\title{
SINGULARIDAD, FORMA Y GOBIERNO LUCRECIO Y LOS TÉRMINOS DE UN REPUBLICANISMO MATERIAL Y SALVAJE
}

\author{
Singularity, Form, and Governing \\ Lucretius and the Elements for a Wild and Material Republicanism \\ Gonzalo Díaz-Letelier \\ Universidad Metropolitana de Ciencias de la Educación, Chile \\ gonz.diaz.letelier@gmail.com
}

A propósito de: Lezra, Jacques. (2020). República salvaje. De la naturaleza de las cosas. Santiago de Chile: Ediciones Macul. 333 pp.

\begin{abstract}
Cetera de genere hoc mirande multa videmus, quae violare fidem quasi sensibus omnia quaerunt, ne quiquam, quoniam pars horum maxima fallit propter opinatus animi, quos addimus ipsi, pro visis ut sint quae non sunt sensibus visa; nam nihil aegrius est quam res secernere apertas ab dubiis, animus quas ab se protinus addit. ${ }^{1}$
\end{abstract}

Lucrecio, 1976: v. 462-468

En su libro República salvaje. De la naturaleza de las cosas (2020), Jacques Lezra plantea la cuestión de lo común en relación con la traza del registro imaginal y literario de la ontología de la república -en una cierta estela de Demócrito, Epicuro, Lucrecio, Maquiavelo, Marx y Althusser, y por ello también de Platón y Aristóteles, astillados todos ellos y sobre todo estos últimos, en tensión con la performance de su sobrevida espectral en algunas escenas de lectura más o menos institucionalizadas como buenas artes en el estudio de los "clásicos". En relación con la discusión sobre el estatuto ontológico del materialismo dialéctico de Marx -que pasa por nombres como Jacques Derrida o Alain Badiou, entre muchos otros-, Lezra marca una sustracción que en su diferencial se retrotrae y proyecta a Tito Lucrecio, en una vuelta al materialismo aleatorio en sus fuentes antiguas y sus derivas como hilos más o menos secretos a través de la modernidad hasta hoy. Lo que sigue no es una glosa del textil

\footnotetext{
${ }^{1}$ En este caso, permítaseme traducir por mi cuenta y error: "Muchos otros espectáculos de este género vemos, / que tienden a violar la fe en casi todos los sentidos, / pero no hay caso, porque la mayor parte de los engaños / proviene de lo opinado por el alma, de las cosas que ella misma añade, / como vistas, cuando no han sido vistas sensiblemente; / pues nada es más difícil de discernir y abrir a la duda, / que aquello que el alma ha puesto de antemano delante de sí".
} 
de Lezra, menos un panorama exhaustivo, sino un desvarío retroversivo respecto de su asunto. Acampar a la orilla del texto, recibiendo sus envíos y extravíos en el desvío hacia los que podrían ser sus problemas iniciales -hacia ningún "origen", por supuesto, sino solo atendiendo a la problemática facticidad de ciertas tradiciones consagradas y demasiado fiables por mor del uso hermenéuticamente configurador del hábito. Del hábito configurador, del pensamiento dormido, del "instinto filosófico" respecto del cual hay que estar vivos, quizás hasta despertar. Intento aquí hacer explícitamente perceptibles solo algunas de las trazas de unas coreografías universitario-policiales para nada inusitadas del discurso de la "filosofía primera", monumentalizadas, canonizadas y canónicas literariamente en el ámbito de la llamada "filosofía política", a las que Lezra en su libro asedia, desenhebrándoles el paso de su danza consuetudinaria en la agostiza pista de baile de los campos disciplinarios que la cultivan, y en vistas de sus rendimientos en la cruenta escena material de los tiempos que corren.

¿Cómo pensar la política de la república en un sentido material? ¿De qué modo la materia puede ser puesta en analogía con la república? ¿Cómo pensar una república material, no caída en el fundamentalismo principial ni en la substancialización identitaria que habilitan el devenir antidemocrático y autoinmunitario de la república? En su libro, Lezra piensa la posibilidad de una república salvaje -y las curvas monstruosas hacia las repúblicas ideales-al hilo de una magnífica lectura del poema $D \bar{e}$ rērum natūra del filósofo romano Lucrecio, escrito en el siglo I a.C. Lezra lee a Lucrecio en la dispersión de sus múltiples registros (poética, pedagogía, filosofía de la naturaleza y moral, etc.), los que habitualmente son apropiados en su especificidad por diversas disciplinas (Lezra, 2020: 46-47). El poema de Lucrecio declara poéticamente la filosofía de la naturaleza atomista de Demócrito y la filosofía moral del placer de Epicuro, enunciando en sentido materialista la vida de relación del hombre -antes que las entidades, hay relación- en un cosmos sin dioses, e intentando liberarlo de su temor a la muerte, en la medida en que el terror a la finitud y a la indeterminación lo lleva a proyectar supersticiones sobre dioses y, además, a acogerse a tiranos que se pretenden omnipotentes, como suplementos psíquicos y políticos al ansia de inmortalidad y orden ideal. Tarea infinita la de liberarse el hombre de esto último, dado su recurrente "olvido" de la dimensión radicalmente material de la naturaleza en general y de la vida humana en particular -efecto de la misma cadencia material de todo saber. Dimensión salvaje una y otra vez descubierta por el pensamiento serenamente espantado, y una y otra vez recubierta por la espectralidad implicada en la aterrada maximización de la fantasía y el lenguaje. Tarea infinita y ardua, pues, como anuncia Lucrecio, "nada es más difícil de discernir y abrir a la duda, / que aquello que el alma ha puesto de antemano delante de sí" (Lucrecio, 1976: v. 467-468).

República salvaje. De la naturaleza de las cosas (2020) es un libro escrito en español y publicado en Chile. Su primera sección, titulada "Peripecias", en efecto corresponde a las sesiones de un seminario que Lezra ofreció, en junio de 2017, en el Departamento de Filosofía de la Universidad Metropolitana de Ciencias de la Educación, en Santiago de Chile; Lezra desarrolla allí una lectura del Dē rērum natūra de Lucrecio en relación con las gramáticas de la naturaleza, la república y el poema, en la tensión dinámica entre forma y clīnāmen (desvío). La segunda sección, 
"Contrainstitución de la república", elabora a partir de esa tensión dinámica un concepto de republicanismo material y salvaje, en clīnāmen respecto de la filosofía política tradicional en sus apropiaciones contemporáneas de la institución del saber universitario. La tercera sección, "La república desde la violencia", es una conversación entre Jacques Lezra y el profesor Miguel Vásquez de la Universidad Complutense de Madrid, que versa sobre violencia y republicanismo, en el diferencial entre terror y terrorismo. República salvaje. De la naturaleza de las cosas (2020) es un libro en español vinculado a una trilogía en inglés donde Lezra desarrolla el argumento de que el gobierno republicano depende de producir e instituir conceptos defectivos de asociación política. De esa trilogía hacen parte Wild Materialism (2010), On the Nature of Marx's Things (2018) y un tercer título por venir anunciado hasta ahora como Defective Institutions. A Protocol for the Republic.

El "republicanismo clásico" implica una concepción de institución fuerte, con su gramática metafísica del sujeto y la presencia - de teleología, representación y ley, de estabilidad orgánico-institucional e identidad fuerte de pueblo o ciudadanía política. Institución autosubsistente (substantia) en la forma estable de su orden: subsiste "en forma" a la contingencia democrática que intenta transformarla. En la consideración de esta fórmula puede saltar una pregunta, la que asalta a Lezra: ¿cómo evitar el mitologema de que la democracia necesita instituciones fuertes? Se trata de un ritual narrativo del acontecimiento que presupone que la democracia es una substancia que sobrevive a la contingencia. Pero conservar la democracia sería, de este modo, conservar el orden representacional y representacionalmente en condición de régimen fáctico. En contraste con ello, Lezra señala hacia "la tensión absolutamente lucreciana entre evento y substancia" (Lezra, 2020: 27) y muestra que si pensamos el quiasma analógico entre materia y república, de ello podemos derivar la conceptualidad defectiva de una "república material" hecha de instituciones defectivas. Pensar el quiasma analógico entre materia y república significa, por una parte, concebir la forma como potencia inmanente a la materia (efecto de la dinámica de la combinatoria de los átomos) y, por otra, concebir la república en el desgarro de sus singularidades y en su intraducibilidad representacional (proliferación material y anárquica de mundos posibles en formas defectivas de asociación política).

De Platón a Lucrecio, de la república ideal a la república material, el poema de Lucrecio se halla en clīnāmen respecto del concepto platónico de república. A modo de comentario en excurso, apuntaría aquí algunas cuestiones relativas a Platón. Que el elemento de la república de Platón sea inteligible (Platón, 1903a: VII, 523b; Lezra, 2020: 152) significa, en un sentido decisivo para el argumento de Lezra, que lo común y la comunicación pueden ser reducidos a la trascendencia de la unidad ideal del sentido -por la vía de la reducción noética del elemento aleatorio y conflictivo de la singularidad. Platón sostiene, en efecto, que la idea ( $\imath \delta$ ś $\alpha$ ) es la

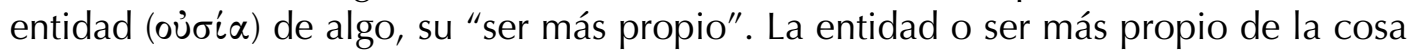
es el aspecto ( $\left.\varepsilon \varepsilon^{\prime} \delta \circ \varsigma\right)$ estable y no sensible que mantiene a la cosa en su identidad y 


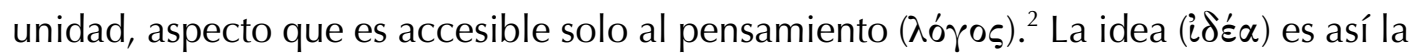

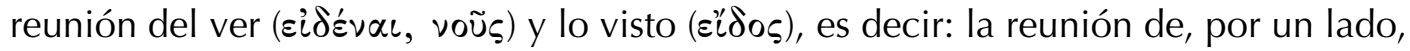
el pensamiento como un ver del alma, y, por otro, el aspecto universal y necesario ${ }^{3}$

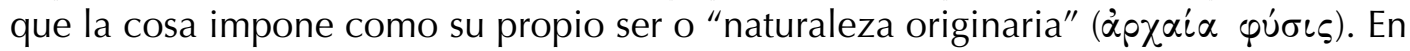

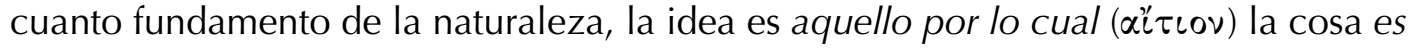
lo que es y sigue siendo lo que era, pese a todos sus cambios accidentales. Y en cuanto trascendente respecto de la multiplicidad sensible, la idea tiene los atributos del ser de Parménides: es una, eterna, inmutable y perfecta.

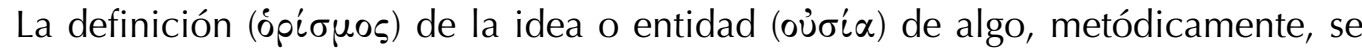

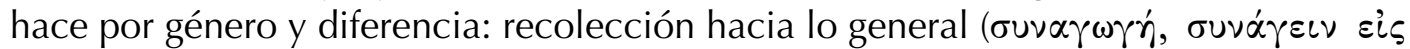

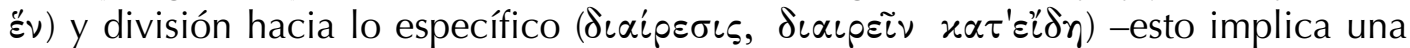
dialéctica de lo uno y lo múltiple en lo ideal: la idea de 'animal' subsume en sí, en su universalidad más amplia, las ideas menos universales de "gato" y "perro". La universalidad tiende hacia la unidad, hacia lo común o la comunidad del género

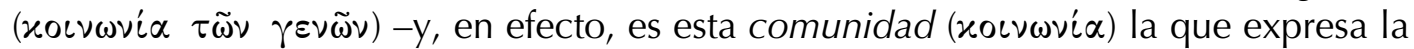
participación ( $\mu \varepsilon \tau \varepsilon \dot{\xi} \xi \varsigma)$ y la perfección ( $\tau \varepsilon^{\prime} \lambda \varepsilon\llcorner o \nu)$ de la cosa en la idea: en qué medida comparte con otras el carácter propio de su clase ideal. A partir de lo Uno (Platón, 1903b: 253b-8) se despliega así un vértice cadente en que lo ideal va multiplicándose, especificándose, dividiéndose hacia las ideas más particulares o especies ínfimas

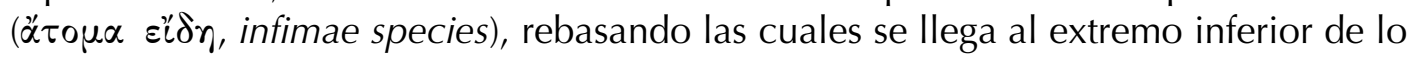
que ya ni siquiera se subordina a especie alguna: se desciende a lo singular que es en cuanto tal indefinible, inesencial, indeterminado y por lo mismo ilimitado (ä $\pi \varepsilon \iota \rho \circ \nu$ ) (Platón, 1903c: 16d7), resto huidizo, indecidible e ingobernable por el pensamiento. Toda la constelación del verbo latino cadere -"caer"-, vinculada en el pensamiento de Lucrecio a la declinación de los átomos, aparece aquí conjurada como tendencia al no-ser: acaecer, caso, acaso, cadencia, ocaso, accidente, etc. ${ }^{4}$ Lo uno singular res-

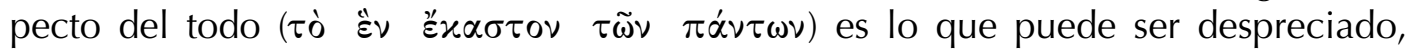

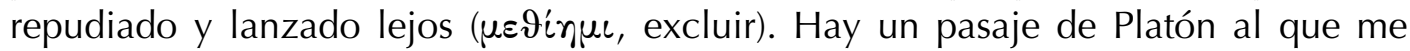
gustaría señalar:

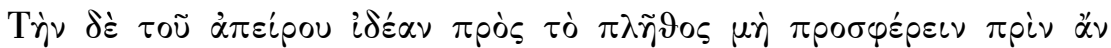

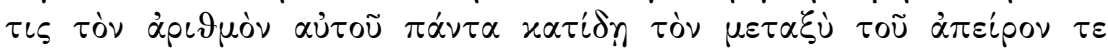

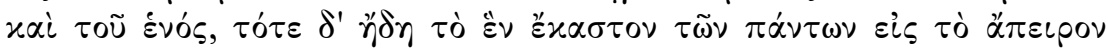

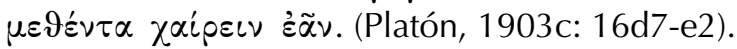

Pero la idea de infinito no ha de aplicarse a los muchos antes de haberse hecho cargo de su número total, número que se halla entre el uno y el

\footnotetext{
${ }^{2}$ La entidad de la cosa, el aspecto estable y no sensible que mantiene a la cosa en su identidad

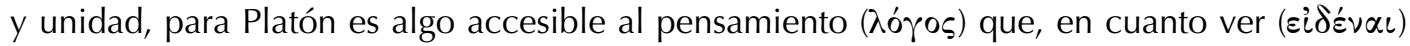
del alma, es intuición intelectual (voũs).

${ }^{3}$ La familia léxica latina relativa a la ūniversālitās traduce del griego al término $\varkappa \alpha \vartheta o ́ \lambda o u, ~ e s$ decir: que se impone sobre todo caso particular, que se cumple para la cosa en todo lugar. Lo

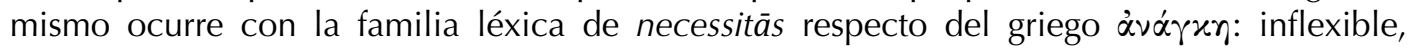
inquebrantable, que se impone y se cumple siempre, en todo momento.

${ }^{4}$ Lezra: en la declinación de los átomos, "la caída es siempre y en cada caso: un evento" (Lezra, 2020: 161; ver también 218, 241 y 313).
} 
infinito; una vez sabido este número, lo uno singular respecto del todo podrá ser repudiado y relegado al infinito.

En este pasaje del Filebo encontramos una determinación inmunitario-metafísica de la "inmundicia" (in-mundus / $\dot{\alpha}-\varkappa 0 \sigma \mu \grave{\alpha} \alpha$ ) o, digámoslo con su violencia, de la mierda. ${ }^{5}$ Corresponde al residuo de lo infinito/indeterminado ( $\left.\tau \grave{\alpha} \alpha ́ \pi \varepsilon \iota \rho o \nu\right)$, lo último,

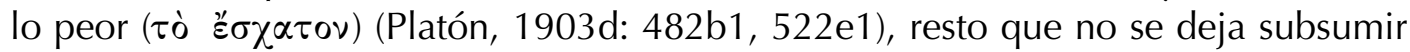
en lo ideal. Lo fecal expulsado del corpus orgánico. Ahora, la cuestión de la

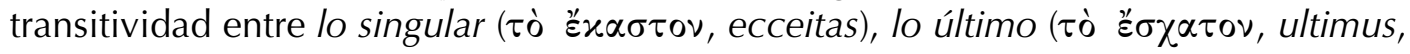

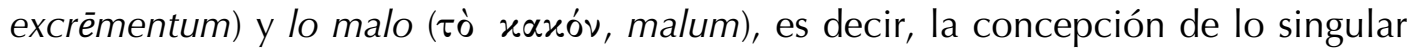
como lo último, como "lo malo" e "inmundo", no se puede entender si no es sobre el fondo de la cuestión teológica platónica: la unidad de lo ideal en lo Uno, divino, bello y verdadero: la idea de bien. Si la unidad de las cosas sensibles se funda en la idea, ¿en qué se funda la unidad de las ideas? Platón responde a este enigma: la unidad de

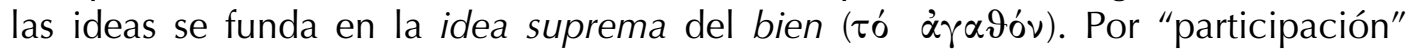

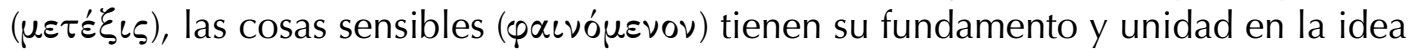

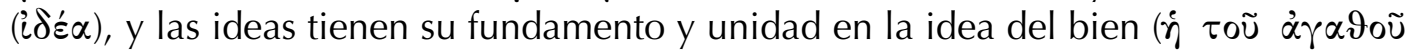

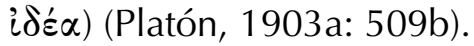

La dimensión arcóntica de la idealidad platónica, la estabilidad formal y unitaria

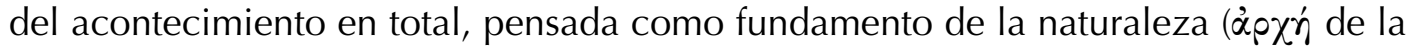

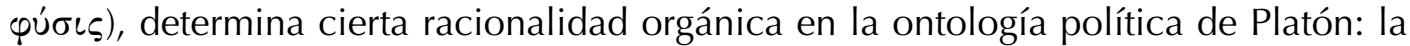
multiplicidad, aleatoriedad y contradicción de lo sensible tienden, en su movimiento natural ascendente, a subsumirse en la unidad del elemento universal de la idea $-y$ en el arcontado o estructura jurídico-institucional de la ciudad ideal, por supuesto. El énfasis de este aspecto en la ontología política de Platón determina una escena de lectura largamente sedimentada, que entre otros de sus efectos ha puesto histórica e historicistamente en juego un concepto fuerte de institución, al hilo de una desmaterialización de la república. Se trata de una tradición que, desde Platón y pasando por la teología cristiana y la llustración, Ilega hasta nuestros días. A contrapelo de ello, Lezra lee en Lucrecio el gesto de un pensamiento que, en lugar de inmunizarse para ponerse en forma, reconoce su carácter material e incorpora el carácter aleatorio y radicalmente heterogéneo de la singularidad y la singularización de la naturaleza material en general. Frente al pensamiento unitario de Platón, articulado fun-

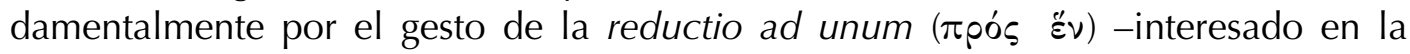
gramática del mundo como texto soberano-, el pensamiento de Lucrecio sería traza de un pensamiento hospitalario: le interesan esos lugares donde la gramática del mundo se desgarra, y por eso puede pensar una república material y salvaje hecha de instituciones defectivas que den cuenta de la potencia histórica de los pueblos y su eventualidad no caída al régimen representacional fuerte.

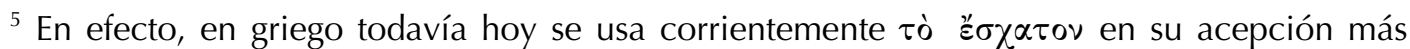
violenta pero reprimida, de mierda -en lo presentable, tal acepción es normalmente reprimida, pongamos el caso, por los helenistas hispanos que elaboran los diccionarios corrientes de griego-español.
} 
Si toda vida es una forma de vida, la lógica teo-onto-antropológica que proyecta el platonismo occidental -en cuanto lógica de gobierno y asociación política- implica, en primer término, la separación entre vida y forma, y la proyección de la forma como anterior a la vida - de tal manera que la vida no puede tener con su forma otra relación que no sea la obediencia a su régimen de deuda. En segundo término, la lógica ontoteológica de gobierno implica la articulación de la forma de vida en relación a un principio -el fantasma hegemónico como interdicto hermenéutico y normativo, que en griego se expresa en la "relación a lo uno" ( $\pi$ pós हैv). Pero en la mirada de Lucrecio, tal fantasmática -esse ea quae rerum simulacra vocamus- es tensionada en su hegemonía por el clīnāmen o movimiento discordante de la vida que se escapa, con la imagen en fuga de una república salvaje. El clīnāmen es aquí el concepto clave de una gramática defectiva de la apertura, el encuentro y el desvío, de la violencia originaria y el resto ingobernable política y categorialmente.

Me parece que la lectura que hace Lezra del oceánico poema de Lucrecio nos permite volver a explorar, desde otros motivos, estrategias y artesanías, al menos un par de cuestiones articuladoras de la imaginación política occidental desde el ensamble de la tradición platónica con la del tomismo aristotélico en el canon universitario de la filosofía primera: 1) la trama representacional de relaciones entre potencia y acto mediadas finalísticamente, al momento de pensar la eventualidad del movimiento y de la vida de relación entre entidades; y 2) la lógica proposicional que, al problematizar la relación entre la entidad (substancia) y las categorías, sistematiza el orden del juicio clasificatorio en virtud del cual el singular/plural (lógica de la diferencia) deviene relación a lo uno: el singular deviene "caso" particular de un universal teleológicamente informado (lógica del gobierno en cuanto imperium).

Platón, por supuesto, como bien lo vio su lector Maquiavelo varios siglos más tarde, también enfrentó la dimensión material de la historia en su carácter aleatorio y conflictivo -ya sea pensando la guerra civil $(\sigma \tau \alpha \dot{\sigma} \iota \varsigma)$ en República (Platón, 1903a: 470b), o incluso en el Timeo (Platón, 1903e: 52b), en esa dimensión del no-lugarque-da-lugar $(\chi \omega \dot{\omega} \rho \alpha)$ que se halla antes de toda posible relación mimética entre lo sensible y lo inteligible. Pero allí donde Platón retrocede ante algo abismal y aterrador, conjurando lo que se le aparece como la tendencia al no-ser del singular como lo último (๕̌ $\sigma \chi \alpha \tau \circ \nu)$-subsumiéndolo o aniquilándolo en nombre del orden ideal de la república-, la pedagogía del terror del poema sobre la naturaleza de Lucrecio acoge ese secreto una y otra vez descubierto y olvidado como el corazón de un pensamiento serenamente espantado, que busca conjurar, además de la necia violencia supersticiosa y sacrificial de los hombres, los efectos autoinmunes de una república ideal derivada de ello. Jacques Lezra escribe:

Dos milenios después de que se redactara (antes del 50 antes de Cristo), la sombra del "Dē rērum natūra» de Lucrecio cae sobre las disciplinas "populares" de la filosofía, la historia y la crítica literaria, los estudios religiosos, los clásicos, la filosofía política y la historia de la ciencia, entre otras. ¿Cómo dar cuenta de la modernidad de la obra? ¿O, quizá, de su impresionante resistencia ante todo esfuerzo de alinearla con las preocupaciones de una época (ya sea el momento de su escritura; el de su redescubrimiento; su primera y escandalizada recepción; su persistencia en tanto monstruo filosófico siniestro que vaga por los áticos de la 
Ilustración; su incómodo flirteo con las críticas al determinismo; su regreso a los debates académicos a finales del siglo veinte)? ¿Qué significa $D \bar{e}$ rērum natūra para nosotros? (Lezra, 2020: 32).

Repensar lo político con Lucrecio conlleva un movimiento o dislocación epocal

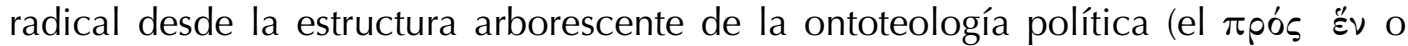
afirmación sacrificial de lo uno como incorporación orgánica bajo un principio trascendental) a la afirmación anárquica y no sacrificial de las multiplicidades inmanentes de lo vivo, proliferación de la vida pagana, de sus éjidos y sus heterocronías. La potencia del viviente como resto habría que pensarla, pues, en tensión destituyente respecto de la ficción imaginal de la trascendencia del poder soberano -el fantasma hegemónico como "trono vacío" o non res- y de su proyección económico-gubernamental en la inmanencia como captura, modelamiento, productivización o sacrificio de la vida -tecnología de crianza humanista. Como si fuera una ontología modal barroca, la "expresión" de la potencia implica la "destrucción" del principio de representación que la captura. En ello se juega la imagen en fuga de la república.

\section{BIBLIOGRAFÍA}

Lezra, Jacques. (2020). República salvaje. De la naturaleza de las cosas. Santiago: Macul.

Lezra, Jacques. (2018). On the Nature of Marx's Things. Translation as Necrophilology. New York: Fordham University Press.

Lezra, Jacques. (2010). Wild Materialism. The Ethic of Terror and the Modern Republic. New York: Fordham University Press.

Lucrecio, Tito. (1976). Dē rērum natūra / De la naturaleza. Barcelona: Bosch.

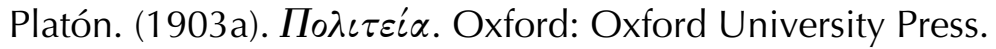

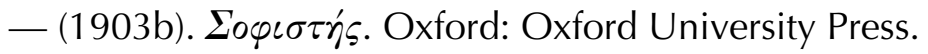

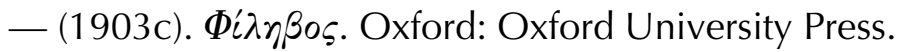

- (1903d). Гoprias. Oxford: Oxford University Press.

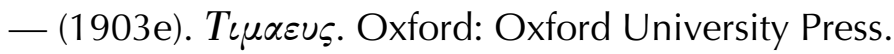

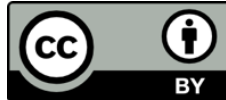

